How to cite: Beilicci, E., Beilicci, R. (2021) Influence of Rainfall Characteristics on Runoff in a Small Watershed. 2021 "Air and Water - Components of the Environment" Conference Proceedings, Cluj-Napoca, Romania, p. 141-148, DOI: 10.24193/AWC2021_13.

\title{
INFLUENCE OF RAINFALL CHARACTERISTICS ON RUNOFF IN A SMALL WATERSHED
}

\author{
Erika Beata Maria BEILICCI ${ }^{1}$, Robert BEILICCI ${ }^{1}$ \\ DOI: 10.24193/AWC2021_13
}

\begin{abstract}
Due to climate change, extreme rainfall is more frequent, and the phenomenon of drought and desertification in some parts of the world is accentuated. Scientists forecast that these trends to continue as the planet continue to warm. An increasingly common phenomenon is the occurrence of flash floods in areas where human intervention on natural conditions has been significant. Over this intervention is superimposed the modification of the characteristics of extreme rainfalls (duration, intensity, height), resulting a series of negative consequences on the ecosystems of the watersheds. For their protection, a more accurate forecast of the size and times of occurrence of the maximum water flows and levels in different sections are needed. This forecast must be made with appropriate methods, such as the use of advanced hydroinformatic tools. This paper analyses the influence of rainfall characteristics on runoff in a small watershed, using rainfall-runoff phenomenon modelling. The modelling is realized using advanced hydroinformatic tool MIKE11, developed by Danish Hydraulic Institute (DHI).
\end{abstract}

Keywords: small watershed, rainfall, runoff, maximum water discharge, maximum water level, Romania, Timis County

\section{INTRODUCTION}

The definition of climate change, in simple words is: climate change describes a change in the average conditions - such as temperature and characteristics of rainfall - in a region of the world over a long period of time. A variety of factors, both natural and human, can influence the earth's climate system. The most important causes of climate changes are the human activities by burning fossil fuels, cutting down rainforests and farming livestock, greenhouse gases emissions in the atmosphere, increasing the greenhouse effect and global warming. (https://climate.nasa.gov/resources/global-warming-vs-climate-change/)

The negative effects of climate change are: more frequent and intense drought, storms, heat and cold waves, changing the maximum and minimum temperature limits in certain areas, rising sea levels, melting glaciers and warming oceans, which can directly harm ecosystems and wreak havoc on people's livelihoods and communities. Declining water supplies, reduced agricultural yields, health impacts

\footnotetext{
${ }^{1}$ Politehnica University Timisoara, Faculty of Civil Engineering, Department of Hydrotechnical Engineering, Spiru Haret Street No. 1/A, 300022, Timisoara, Romania, erika.beilicci@upt.ro, robert.beilicci@upt.ro
} 
in cities due to heat, and flooding and erosion in coastal areas are additional negative effects of climate changes. As climate change worsens, dangerous weather phenomena's (which determine disastrous hydrological phenomena) are becoming more frequent or severe. (https://climate.nasa.gov/resources/global-warming-vsclimate-change/) (https://www.worldwildlife.org/threats/effects-of-climate-change)

The occurrence of extreme precipitation events, due to climate change, produced more rain. This phenomenon becomes more common since the 1950s in many regions of the world. An atmosphere with more moisture can produce more intense precipitation events, which is exactly what has been observed today, frequently. The characteristics of rainfall (intensity, duration, frequency), among other factors (Figure 1), determine the size and duration of maximum water discharges and maximum water levels in the valleys of small watershed, where the risk of occurrence of flash floods is high.

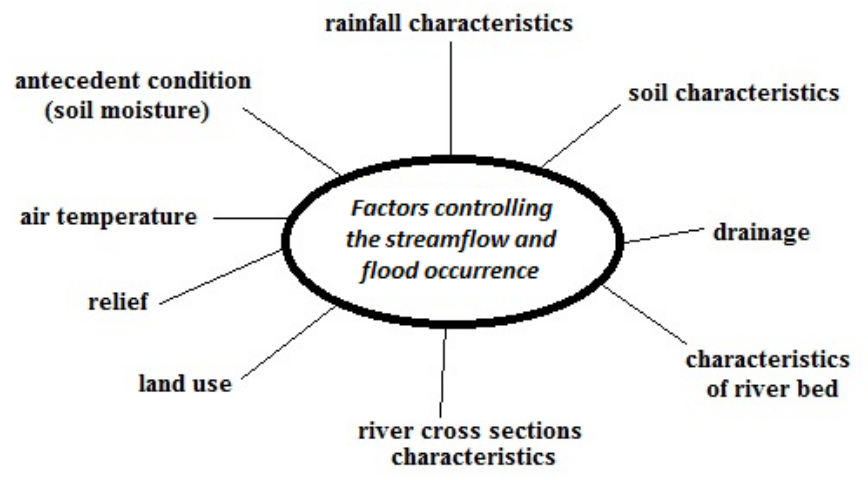

Fig. 1. Factors controlling the streamflow and flood occurrence

The causes of flash floods occurrence are presented in Figure 2. The risk of flash floods occurrence is also increased by the irrational use of land in the hydrographical basin (deforestation, inadequate agricultural techniques, excessive grazing etc.) by changing the characteristics of surface runoff.

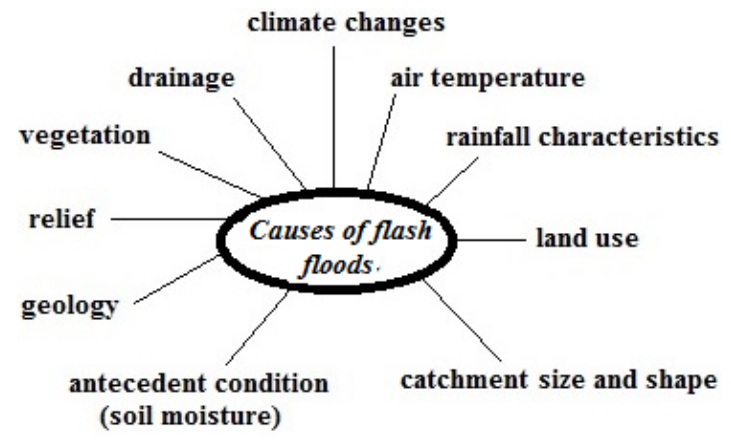

Fig. 2. Causes of flash floods 
These quick-rising floods are most often caused by heavy rains over a short period (usually six hours or less). Flash floods can happen anywhere, low-lying areas with poor drainage are particularly vulnerable. (https://www.nrdc.org/stories/flooding-and-climate-change-everything-you-need-know)

The nature of flash floods makes them rapid and very difficult to predict, they can occur without warning. The effects of flash floods are death or serious injury of people and animals, immediate or long-term property damage, loss of critical infrastructure, deposits of sediment and silt, economic losses.

The study of the influence of rainfall characteristics on runoff is important to determine the risk of rapid floods occurrence in vulnerable areas, respectively to know their extent and to draw up plans to reduce their negative effects.

\section{ADVANCED HYDROINFORMATIC TOOL MIKE11}

MIKE11 is part of the MIKE by DHI software products based on the MIKE Zero platform. MIKE 11 is a professional engineering software package for simulation of one-dimensional flows in estuaries, rivers, irrigation systems, channels and other water bodies. MIKE11 is a 1-dimensional river model. It was developed by DHI Water $\bullet$ Environment $\bullet$ Health, Denmark.

The nucleus of MIKE11 modelling system is the Hydrodinamic Module and forms the basis for most modules: flood forecasting, advection-dispersion, water quality and non-cohesive sediment transport. MIKE11 modelling system is the integrated modular structure with a variety of add-on modules, each simulating phenomenon related to river system, like Rainfall-Runoff module. (MIKE by DHI, 2014a)

The Unit Hydrograph Module (UHM) methods of Rainfall-Runoff module of MIKE11, simulates the runoff from single storm events by the use of the unit hydrograph techniques, applicable in areas where no streamflow records are available or where unit hydrograph techniques have already been well established. Unit hydrograph is a hypothetical unit response of the hydrographic basin to a unit input of rainfall. The Unit Hydrograph Module includes different loss models (constant, proportional) and the SCS method for estimating storm runoff. The excess rain is calculated assuming that the losses to infiltration can be described as a fixed initial and constant loss, a proportional loss (the rational method) or by the SCS curve number method. The excess rainfall is routed to the river by unit hydrograph methods. The module includes the SCS-dimensionless hydrographs as well as facilities for establishing and management of databases with user defined unit hydrographs and time series of recorded rainfall and streamflow. The module calculates simultaneously the runoff from several catchments and includes facilities for presentation and extraction of the results. The output from the module can further be used as lateral inflow to the advanced hydrodynamic module in MIKE 11. (MIKE by DHI, 2014b)

The basic equations are the continuity equation and momentum equation (source Chow et al., 1988):

$$
A \frac{d S_{i}}{d t}=f \cdot r_{\text {ave }} \cdot A-Q_{i}
$$




$$
S_{i}=K \cdot Q_{i}^{p}
$$

where: $S_{i}$ - apparent basin storage; $Q_{i}$ - direct runoff from a basin with consideration of the time of delay (except for base flow); $T_{i}$ - time of delay; $K$, $p$ - constants; $f$ - coefficient of inflow; $r_{\text {ave }}$ - mean rainfall of river basin and $A$ - catchment area.

\section{STUDY CASE}

The influence of rainfall characteristics on runoff in a small watershed was studied on a watershed with the following characteristics (located in Bega River basin, Romania, Timis county) (Figure 4):
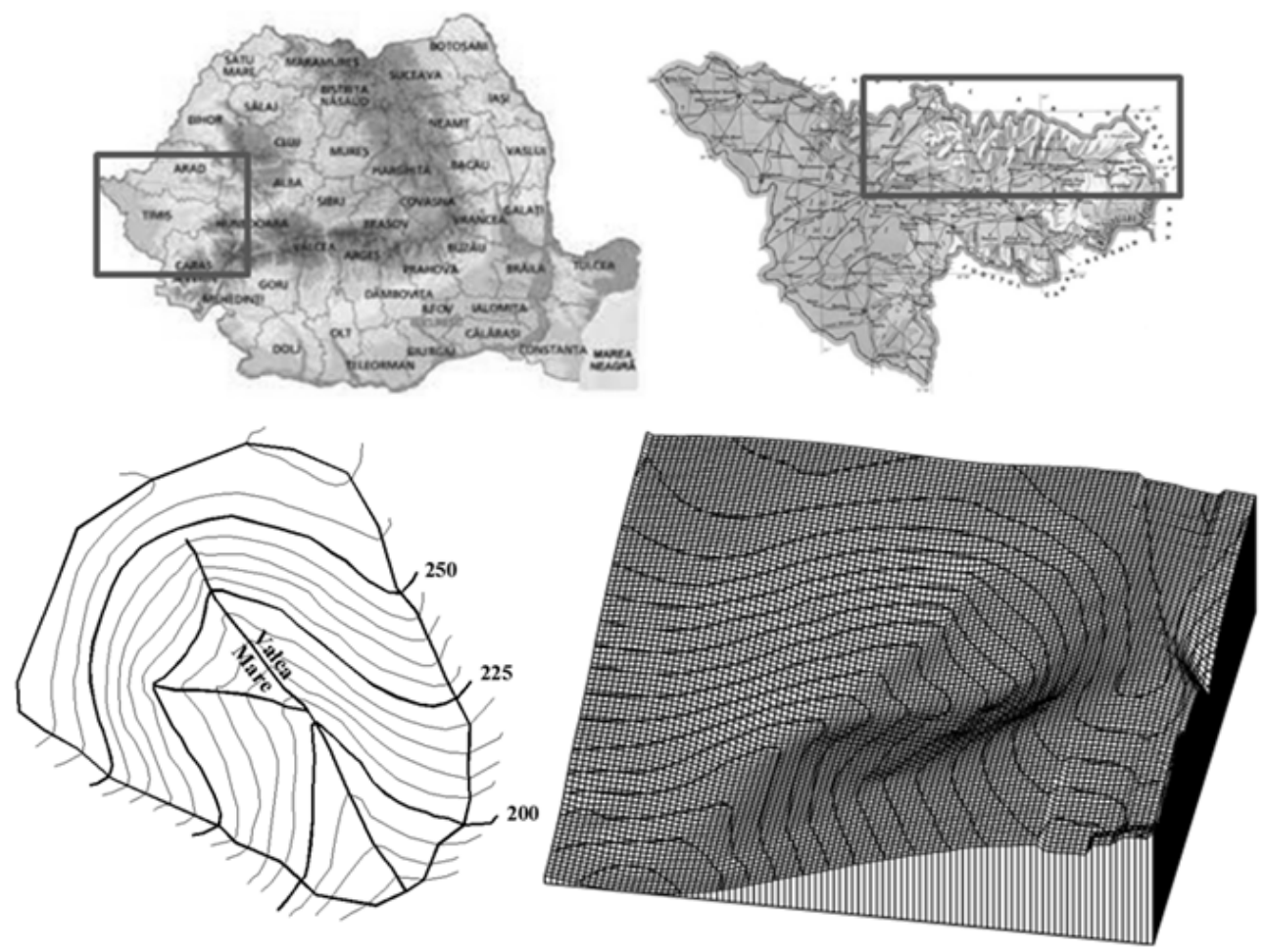

Fig. 4. Studied hydrographical basin.

- watershed average slope: $20.64 \%$

- total area: 235.4 ha

- land use: pasture $\mathrm{CN}=74$

- soil hydrologic group: C (from pedological studies in this area)

- hydraulic length: $3 \mathrm{~km}$.

The precipitation production scenarios are given in the Figures 5 and 6 , and in Table 1 (the total rainfall height is $150 \mathrm{~mm}$ in all 4 scenarios, but the rain duration is different). 

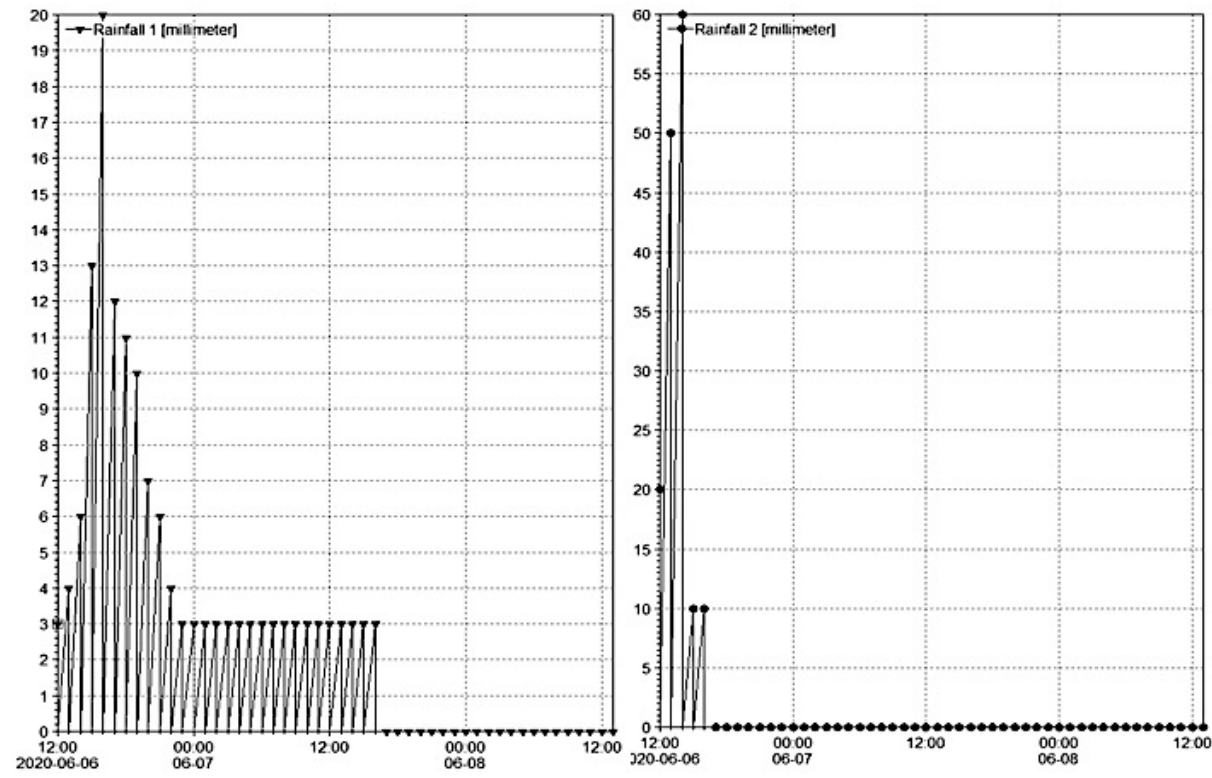

Fig. 5. Rainfall scenarios 1and 2

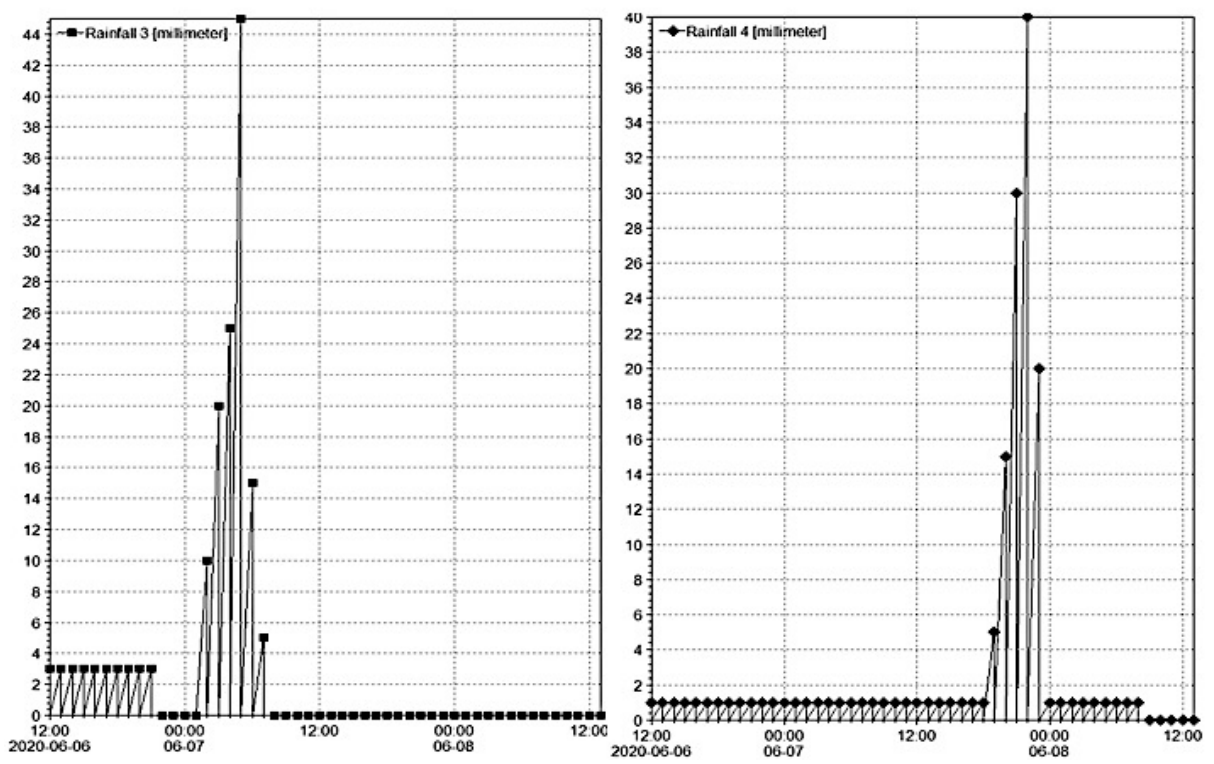

Fig. 6. Rainfall scenarios 3 and 4

The simulation hypotheses were:

- time step: 30 minute

- base flow: 0

- simulation period: 06/06/2020, 12:00:00 PM - 06/08/2020, 1:00:00 PM

- initial abstraction depth: $0 \mathrm{~mm}$ 
- hydrograph method: SCS dimensionless

- enlargement and loss model: SCS generalised

- lag time: curve number method.

\section{RESULTS AND DISCUSSION}

The runoff hydrographs resulting from the simulation can be seen in the Figures 7, 8, 9 and 10 and maximum values of runoff are shows in Table 1.

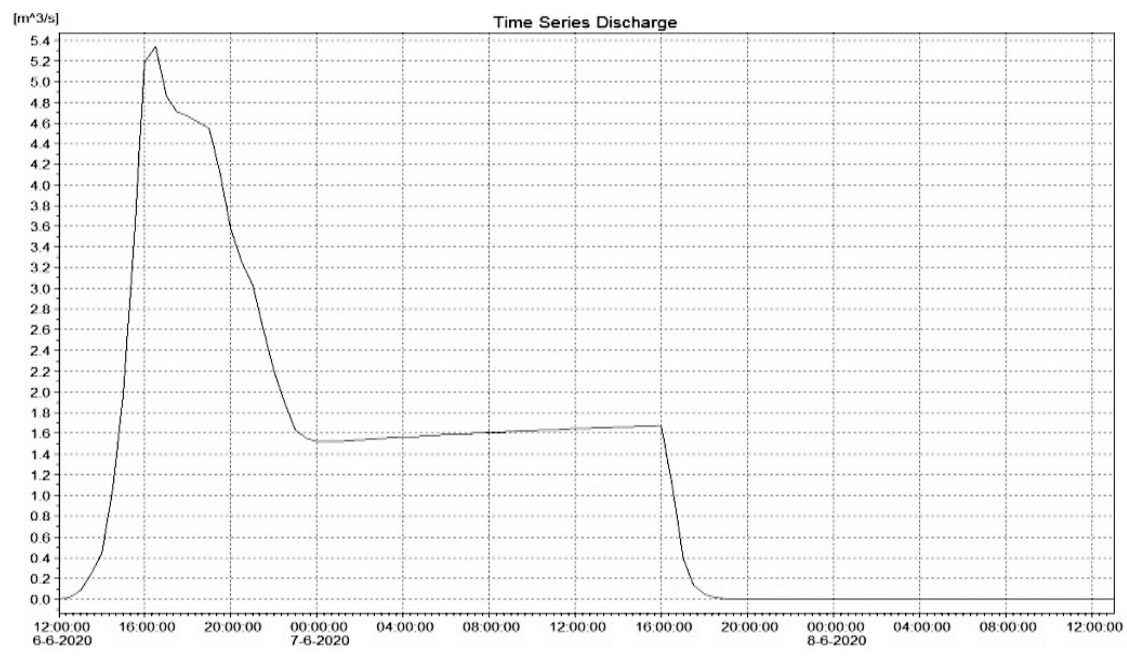

Fig. 7. Simulated runoff hydrograph for scenario 1

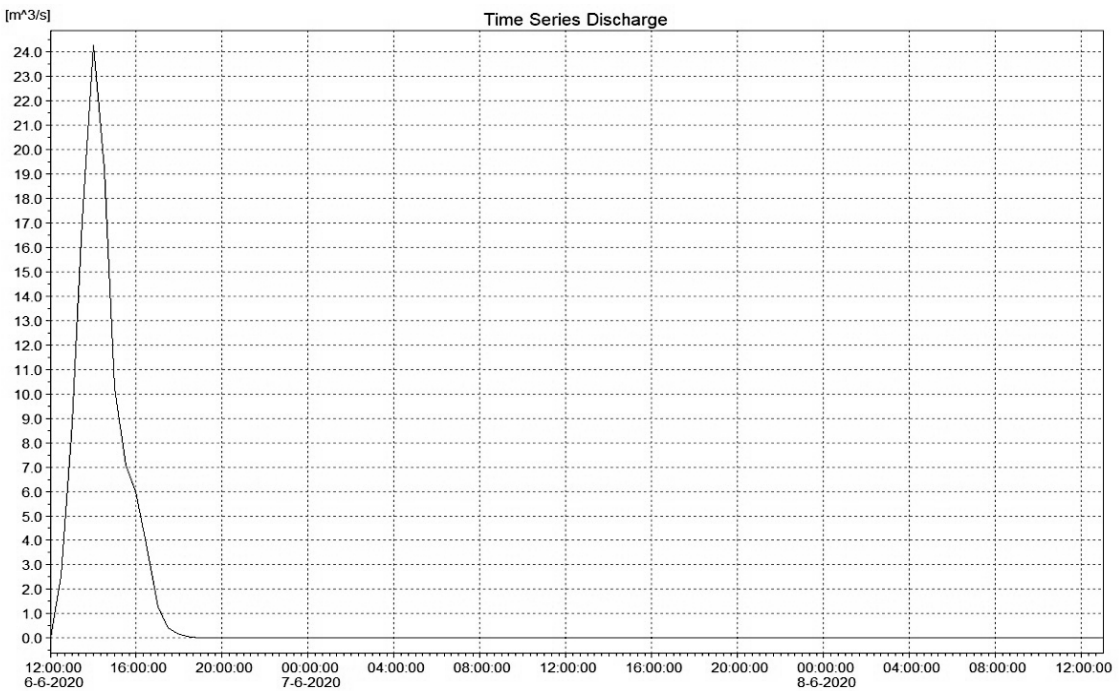

Fig. 8. Simulated runoff hydrograph for scenario 2 


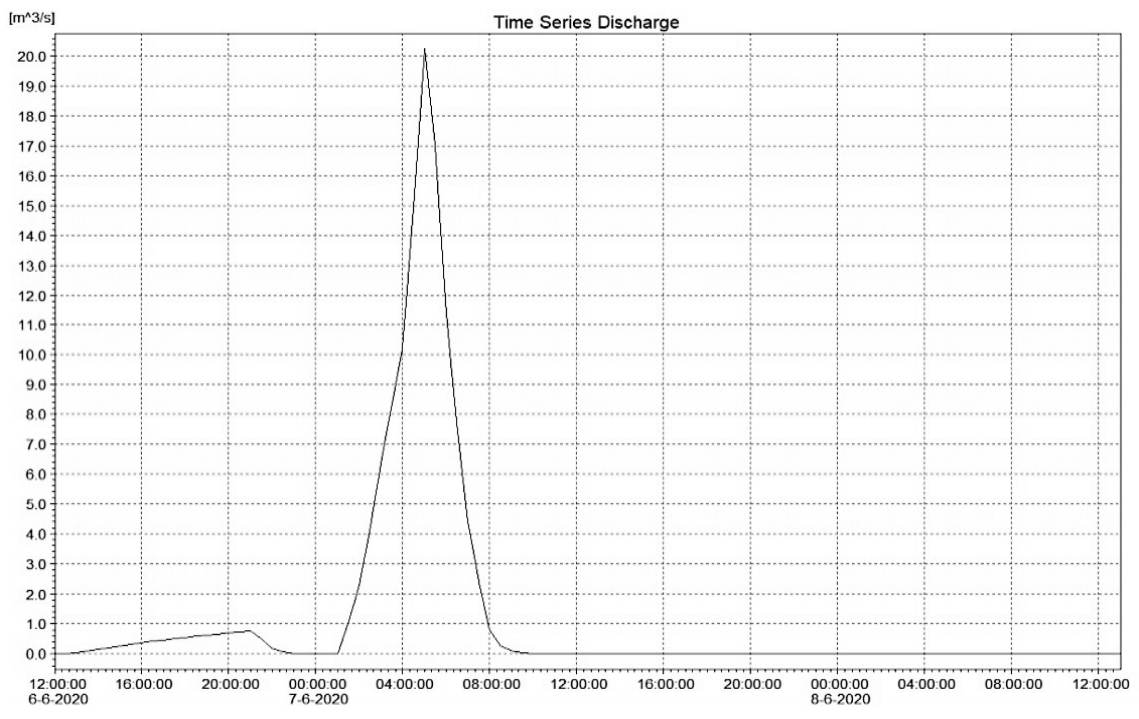

Fig. 9. Simulated runoff hydrograph for scenario 3

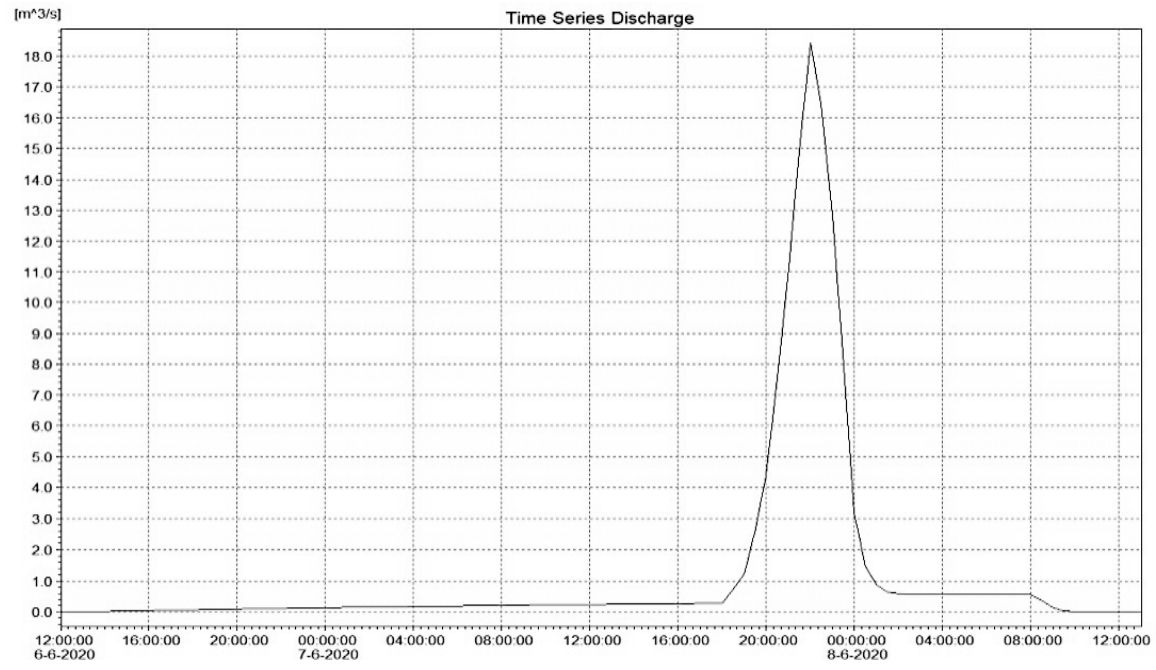

Fig. 10. Simulated runoff hydrograph for scenario 4

The analysis of the results shows the following aspects:

- the time of occurrence of the maximum runoff discharges are correlated with the period of maximum rainfall intensity, because the area of the watershed is small, the delay / concentration times of the flow are short;

- the highest discharge occurs in scenario 2, in which the rain intensity is also the highest, although it is of short duration; 
- the lowest discharge occurs in scenario 1, in which the rain maximum intensity is also the lowest, although the average intensity is not the lowest.

Table 1. The maximum values of runoff and rainfall characteristics

\begin{tabular}{|c|c|c|c|c|c|}
\hline Scenario & $\begin{array}{c}\text { Rainfall } \\
\text { Height } \\
(\mathrm{mm})\end{array}$ & $\begin{array}{c}\text { Rainfall } \\
\text { duration } \\
(\mathrm{h})\end{array}$ & $\begin{array}{c}\text { Rainfall average } \\
\text { intensity } \\
(\mathrm{mm} / \mathrm{min})\end{array}$ & $\begin{array}{c}\text { Rainfall maximum } \\
\text { intensity } \\
(\mathrm{mm} / \mathrm{min})\end{array}$ & $\begin{array}{c}\text { Runoff } \\
\text { maximum } \\
\text { discharge } \\
\left(\mathrm{m}^{3} / \mathrm{s}\right)\end{array}$ \\
\hline 1 & 150 & 29 & 0.086 & 0.333 & 5.3 \\
\hline 2 & 150 & 5 & 0.500 & 1.000 & 24.2 \\
\hline 3 & 150 & 20 & 0.125 & 0.750 & 20.2 \\
\hline 4 & 150 & 45 & 0.055 & 0.666 & 18.5 \\
\hline
\end{tabular}

\section{CONCLUSIONS}

The paper shows the possibility / utility of advanced hydroinformatic tools in the study of the influence of rainfall characteristics on surface runoff in small watersheds. Thus, the maximum flows discharges can be forecast, implicitly determining the maximum water levels, in different cross sections of interest.

Advanced hydroinformatic tools for flash flood simulation are useful for water management professionals, to develop warning and intervention plans in small watersheds with a high risk of flash floods occurrence. In order to achieve an adequate simulation, it is necessary to know the characteristics of the watershed (types of soil, vegetation, relief, surface, mapping of areas with problems in slope stability etc.). The forecasting of maximum levels and discharges in certain sections, based on floods modelling, is useful for designing hydrotechnical works for mitigate to defend / reduce the effects of flash floods. Thus, a coordinated exploitation of all hydrotechnical works and another non-structural measure (like reforestation, land use management) can be achieved, for the sustainable and integrated management of water resources and of small watershed.

\section{REFERENCES}

1. MIKE by DHI (2014a), MIKE11 River and Channel Modelling, Short IntroductionTutorial, Horsholm, Denmark, pp. 1-6.

2. MIKEbyDHI (2014b), A modeling system for rivers and channels, Reference Manual, Horsholm, Denmark, pp. 331-332.

3. Chow V.T., Maidment, D. R., Mays L. W. (1988) Applied Hydrology, McGraw-Hill Book Company, New York, US

4. https://climate.nasa.gov/resources/global-warming-vs-climate-change/ Accesed on 11.01.2021

5. https://www.worldwildlife.org/threats/effects-of-climate-change/ Accesed on 13.01 .2021

6. https://www.nrdc.org/stories/flooding-and-climate-change-everything-you-needknow Accesed on 14.01.2021. 